\title{
Photoallergic Contact
}

\section{Dermatitis due to Ketoprofen and Hydrogenated Rosin Glycerol Ester}

\author{
Tomoko Rindo Naoki Oiso Yoshika Yamadori \\ Ayaka Hirao Shigeru Kawara Akira Kawada \\ Department of Dermatology, Kinki University School of Medicine, Osakasayama, \\ Japan
}

\section{Key Words}

Photoallergic contact dermatitis - Ketoprofen - Hydrogenated rosin glycerol ester .

Compress

\begin{abstract}
A topical application of a nonsteroidal anti-inflammatory drug (NSAID) may induct an adverse reaction of photoallergic contact dermatitis. The occlusive usage may provoke concomitant photoallergic sensitizations to an NSAID and other ingredients. We describe a 58-year-old woman with photoallergic contact dermatitis from ketoprofen and hydrogenated rosin glycerol ester in the applied compress. Our case indicates that photopatch testing with all ingredients is required to verify the actual photoallergen(s).
\end{abstract}

\section{Introduction}

A topical application of a nonsteroidal anti-inflammatory drug (NSAID) may induct an unexpected reaction of photoallergic contact dermatitis. A recent retrospective study evaluating the results of photopatch testing from 2003 to 2007 showed that 21 of 30 patients tested (70\%) had a relevant positive photopatch testing to an NSAID: 9 to piroxicam, 8 to benzydamine, 2 to ketoprofen, 1 to diclofenac, and 1 to acetylsalicylic acid [1]. This result suggests that NSAIDs are common photoallergens.

In Japan, occlusive application of an NSAID for muscle pain is prevalent. This method may provoke a severe systemic photoallergic reaction and concomitant sensitization to photoallergens and allergens [2-4]. 


\section{Case Report}

A 58-year-old Japanese woman visited us with a pruritic, rectangular-shaped, erythematous and vesicular lesion on the right wrist after using compresses containing ketoprofen for 14 days (fig. 1). She played tennis outside twice a week.

The manufacturer of the compress provided us with all of its ingredients. Patch and photopatch testing was done with the ingredients of the compress, sunscreens and cosmetics the patient had used. On patch testing, no positive reaction was observed at day 2, 3 and 4 (ig. 2 ). On photopatch testing, ketoprofen $1 \%$ pet. and hydrogenated rosin glycerol ester $10 \%$ pet. elicited erythema and papules 1,2 and 3 days after UVA irradiation $\left(4 \mathrm{~J} / \mathrm{cm}^{2}\right)$ (fig. 2).

\section{Discussion}

The patient showed photoallergic contact dermatitis from ketoprofen and hydrogenated rosin glycerol ester on the right wrist. Cases of photoallergic contact dermatitis from ketoprofen have been documented [2-5]. Ketoprofen is an NSAID derived from propionic acid and a photosensitizing agent of photoallergic contact dermatitis. The risk of severe symptoms as prolonged photosensitivity, concomitant sensitization to other photoallergens and/or allergens, and spreading the eczematous reaction beyond the site of ketoprofen application has been shown [2-5].

Photosensitivity to rosin has been reported [6]. Shao et al. [7] found out that esterification of rosin with polyalcohols still contained unmodified material to which the patients might have reacted as contact allergen, even though esterification of rosin reduced its allergenic activity. We previously reported a case of concomitant development of photoallergic contact dermatitis from ketoprofen and allergic contact dermatitis from hydrogenated rosin glycerol ester and menthol [4]. We postulated that the patient had a simultaneous photosensitization to ketoprofen and hydrogenated rosin glycerol ester.

In Japan, compresses containing an NSAID are widely used for muscle pain, and photoallergic contact dermatitis from NSAID is one of the most common adverse reactions. Patch and photopatch testing with all ingredients is needed to verify the actual allergen and photoallergen in each case. 
Fig. 1. Initial presentation of the right wrist.

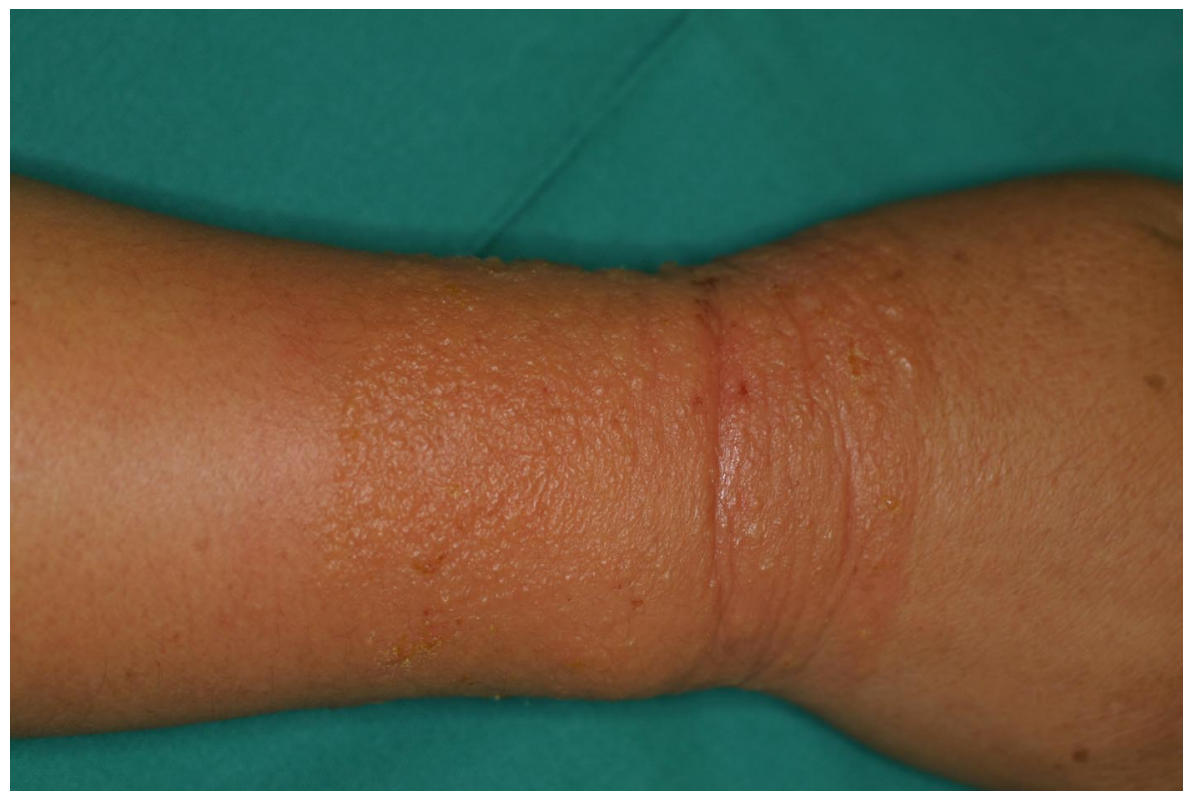

Fig. 2. Patch testing showed negative reaction on day 4 (right side). Photopatch testing showed positive reactions to ketoprofen $1 \%$ pet. and hydrogenated rosin glycerol ester $10 \%$ pet. 3 days after UVA irradiation $\left(4 \mathrm{~J} / \mathrm{cm}^{2}\right)$ (left side).

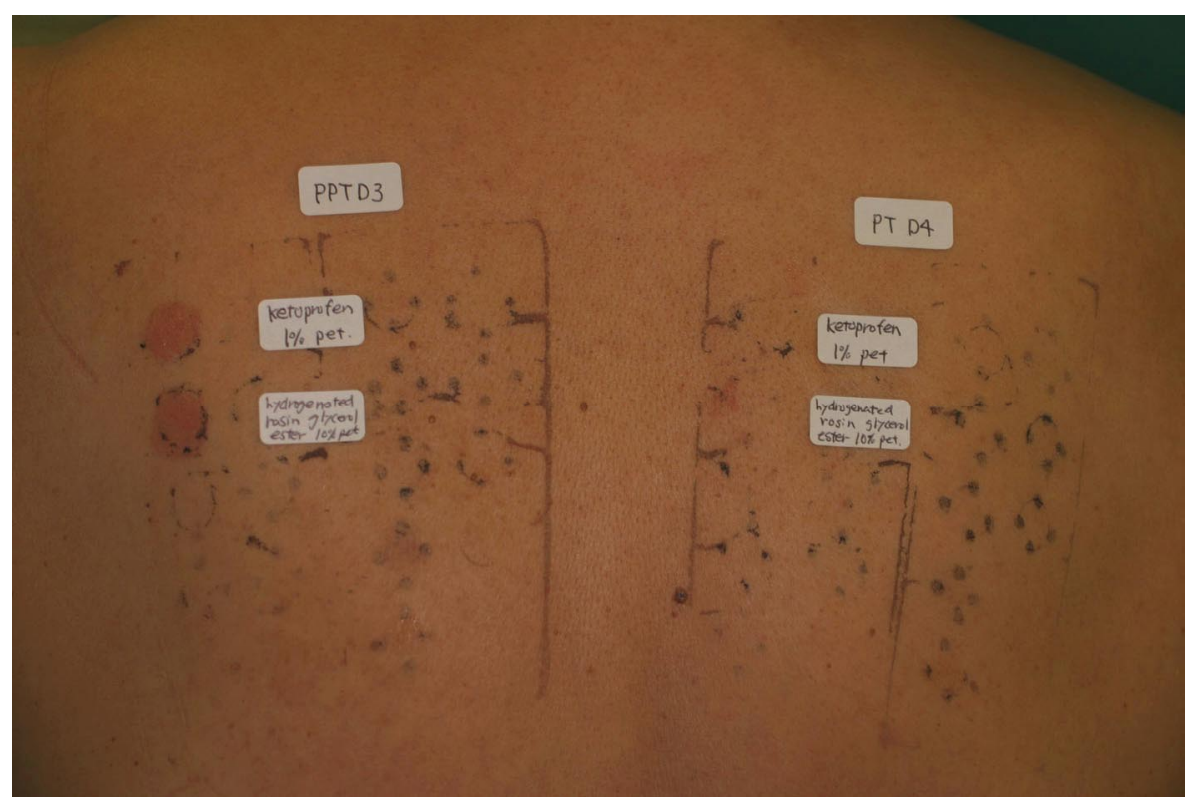




\section{References}

1 Cardoso JC, Canelas MM, Gonçalo M, Figueiredo A: Photopatch testing with an extended series of photoallergens: a 5-year study. Contact Dermatitis 2009;60:325-329.

2 Izu K, Hino R, Isoda H, Nakashima D, Kabashima K, Tokura Y: Photocontact dermatitis to ketoprofen presenting with erythema multiforme. Eur J Dermatol 2008; 18:710-713.

-3 Kawada A, Aragane Y, Asai M, Tezuka T: Simultaneous photocontact sensitivity to ketoprofen and oxybenzone. Contact Dermatitis 2001;44:370.

-4 Ota T, Oiso N, Iba Y, Narita T, Kawara S, Kawada A: Concomitant development of photoallergic contact dermatitis from ketoprofen and allergic contact dermatitis from menthol and rosin (colophony) in a compress. Contact Dermatitis 2007;56:47-48.

5 Matthieu L, Meuleman L, Hecke EV, Blondeel A, Dezfoulian B, Constandt L, Goossens A: Contact and photocontact allergy to ketoprofen. The Belgian experience. Contact Dermatitis 2004;50:238-241.

6 Andersen KE, White IR, Goossens A: Colophony; in Frosch PJ, Menné T, Lepoittevin JP (eds): Contact Dermatitis, ed 4. Heidelberg, Springer-Verlag Berlin, 2006, pp 466-467.

-7 Shao LP, Gäfvert E, Karlberg AT, Nilsson U, Nilsson JL: The allergenicity of glycerol esters and other esters of rosin (colophony). Contact Dermatitis 1993;28:229-234. 